\title{
NIH at the crossroads
}

The director of the US National Institutes of Health has laid out a plan that would align the world's largest biomedical research agency more closely to the future shape of the life sciences. It deserves political support.

$\mathrm{T}$ he National Institutes of Health (NIH) has reached a critical moment in its history. After a remarkable surge in its budget — from some $\$ 13$ billion in 1998 to $\$ 27$ billion this year the agency will be under more pressure than ever before to deliver results. With expenditure on this scale, the time when the NIH can operate more or less independently from its parent Department of Health and Human Services, or even from the White House, may be drawing to a close, raising new questions about the agency's scientific integrity and mission. After years of enthusiastic support in the US Congress, which sets the agency's budget and has shielded it from political interference, the NIH can look forward to a period when it will get more scrutiny — and less largesse — on Capitol Hill.

That's the situation facing NIH director Elias Zerhouni, the former radiologist and administrator at Johns Hopkins University who took over the directorship of the NIH in May last year. Biologists inside and outside the NIH may feel some regret that Zerhouni lacks the overpowering scientific resumé of his predecessor, Harold Varmus. But right now, outstanding administrative flair may be what the expanded agency needs of its director.

Researchers are looking to Zerhouni to provide just that. On 30 September he reached the most significant landmark so far in his directorship, releasing the NIH Roadmap for Medical Research, which, despite a thorough consultation process, bears his clear personal imprint. The plan is shaped to help the NIH do the kind of science - particularly 'translational research', from the laboratory to the bedside - that Zerhouni considers to be most critical to the agency's central mission of improving US public health.

The plan includes initiatives to foster the development of new medical technologies, including some that could aid the highthroughput identification of protein structures. It would create databases and centres, such as a chemical library and institutes for nanomedicine and biomedical computing. The roadmap also instigates a major push to back more interdisciplinary research, and train more people to do it. And it emphasizes speedier and more all-encompassing clinical research, for example by creating regional centres for translational research and better integrating ordinary physicians and their patients into networks of clinical trials.

\section{Backing groups}

The most obvious potential drawback of this ambitious plan is that it may end up diverting money from the individual-investigator grants that have always been the mainstay of the NIH, providing support instead for larger, perhaps more permanent, teams doing interdisciplinary work. Zerhouni says that this merely reflects modern reality, and that the new facilities and structures to be created will make it easier for individual principal investigators to do their jobs. However, efforts to back large groups of researchers and semipermanent centres of excellence have, in many countries over many decades, shown themselves to be less efficient, less merit-focused and more subject to political interference in the allocation of funds, than competitive, peer-reviewed grants for individual researchers. But even if the plan is implemented in full, individual-investigator grants will continue to dominate the NIH's portfolio. The roadmap's contents seem to be a reasonable reflection of the changing currents in biomedical research, which call for systematic and interdisciplinary approaches that are not adequately addressed under the NIH's existing structure.

Another aspect of the plan that has stirred discussion is the creation of ten Director's Innovator Awards, which will give $\$ 500,000$ in funds to individual scientists selected by a peer-review panel. Zerhouni says that this scheme is intended to encourage risky, path-breaking science. But in the absence of clarity over just how this selection will work, there must be some concern that such awards will go to investigators who are already well established.

\section{Ties with industry}

Critics are also questioning aspects of proposals to make it easier for industry to work with the NIH. The roadmap will create a Director's Liaison for Public-Private Partnerships to act as a single point of contact for all of the agency's work with the private sector. But if, as Zerhouni seems to envisage, the agency develops even closer ties with the pharmaceutical industry, questions should be asked in the Congress, where there are some supporters of greater collaboration, about what the pharmaceutical companies are doing in return. For example, might it cap the premium prices that Americans pay for medicines that have often been developed on the back of NIH-funded research projects?

Similarly, the roadmap's vision of a simpler and more transparent process for the regulation of clinical trials may collide with public demands to push regulation in the opposite direction, after recent cases in which patients have died during clinical trials under questionable circumstances.

The roadmap was developed in consultation with scientists both within and outside the NIH. Zerhouni has talked since he arrived at the NIH about the need to foster innovative technologies, to encourage more team science, and to streamline clinical research but he seems to have made an honest effort to incorporate the views of the community. And there is no sign that Zerhouni has allowed either the health department or the White House to impose their political priorities on the plan.

Zerhouni has won public support for this vision from the fiercely independent directors of the agency's 27 separate institutes and centres, who have promised to chip in money from their own budgets to fund interagency efforts that the roadmap says will cost \$125 million next year, building up to $\$ 2$ billion by 2009 . It remains to be seen, of course, what these promises will be worth if money is tight at the institutes when the time comes.

At a congressional hearing on 2 October, Zerhouni fielded a few questions about the roadmap. But he faced just as many, if not more, from lawmakers who were concerned that the NIH had funded research on prostitutes, on transgendered Native Americans and on the sexual habits of older men. Political skills on Zerhouni's part will clearly be as essential for the NIH's own good health as they were for his predecessors. Meanwhile, he deserves credit for laying out a clear vision of what the future of his agency should be. 